4. Казаков Б.П. Ресурсосберегающие технологии управления климатическими параметрами рудников: на примере калийных рудников: дис. ... д.т.н.: 25.00.20 - Пермь, 2001. -315 с.: ил.

5. Казаков Б.П., Шалимов А.В., Сёмин М.А., Гришин Е.Л., Трушкова Н.А. Конвективная стратификация воздушных потоков по сечению горных выработок, ее роль в формировании пожарных тепловых депрессий и влияние на устойчивость проветривания // Горный журнал. - 2014. - № 12. - С. 105-109.

6. Левин Л.Ю. Теоретические и технологические основы ресурсосберегающих систем воздухоподготовки рудников: дис. ... д.т.н.: 25.00.20: защищена 29.04.10 / Левин Лев Юрьевич. - Пермь, 2010. - 275 с.

7. Казаков Б.П., Шалимов А.В. Компоновка теплообменных модулей в системах кондиционирования рудничного воздуха // Горн. информ.-аналит. бюл.: «Геомеханические и геотехнологические проблемы освоения недр севера». - 2015. - S30. - С. 285-290.

8. Клюкин Ю.А. Исследование процесса теплообмена в существующих калориферных установках при увеличении количества воздуха, поступающего в ствол по калориферным каналам // Стратегия и процессы освоения георесурсов: сб. науч. тр. Вып. 11 / ГИ УрО РАН. - Пермь, 2013. - С. 278-280.

9. Газизуллин Р.Р., Левин Л.Ю., Клюкин Ю.А. Разработка систем воздухоподготовки для обогрева шахтных стволов в нормальном и реверсивном режимах проветривания рудников // Горн. информ.аналит. бюл: «Промышленная безопасность минерально-сырьевого комплекса в XXI веке». - 2015. № S7. - C. 19-25.

\title{
РАЗВИТИЕ СИСТЕМ АЭРОГАЗОВОЙ БЕЗОПАСНОСТИ РУДНИКОВ
}

\author{
Е.Л. ГРИШИН \\ Горный институт УрО РАН, г. Пермь
}

\begin{abstract}
Аннотация: В работе представлены результаты промышленных испытаний системы аэрогазовой безопасности калийных рудников, проведенных в условиях рудника 4 рудоуправления ОАО «Беларуськалий». Система обеспечивает непрерывный мониторинг расхода воздуха и качественного состава рудничной атмосферы в рабочей зоне, оповещение диспетчера рудника о выходе контролируемых параметров за пределы допустимых значений, изменение расхода подаваемого на проветривание воздуха по результатам мониторинга, а также - аварийные режимы проветривания участка.

Ключевые слова: аэрогазовая безопасность, калийные рудники, рабочая зона, ядовитые газы, взрывоопасные газы, автоматическая вентиляционная дверь, аэроСеть.
\end{abstract}

Для угольной промышленности характерно уникальное развитие технологий, связанных с обеспечением промышленной безопасности. В частности правилами безопасности [1] регламентируется обязательность применения в угольных шахтах многофункциональных систем безопасности [2]. Самой ответственной частью многофункциональных систем безопасности, наиболее развитой в настоящее время с точки зрения практического применения, являются системы аэрогазового контроля (АГК) или аэрогазовой безопасности (АГБ) [3].

На данный момент времени многофункциональные системы безопасности не нашли широкого практического применения на рудных шахтах в силу уникальности и специфичности отдельных месторождений. Однако отдельные части таких систем реализуются на тех рудниках, где имеют место определенные опасные факторы производства.

Для калийных рудников характерно наличие газового фактора при ведение горных работ. Исследования, проведенные при участии автора на калийных рудниках ОАО «Беларуськалий», подтверждают, что опасность представляет не только выделение метана в результате непосредственного ведения горных работ, но и наличие его высоких концентраций в выработанном пространстве рудников.

На рис. 1 приведен пример развития горных работ горизонта -420 м рудника 3 Рудоуправления ОАО «Беларуськалий». На рисунке видно, какую часть шахтного поля 
занимает на данный момент выработанное пространство. Звездочкой отмечено место проведенных исследований параметров атмосферы выработанного пространства, выполненных при подготовке нового столба лавы к выемке. Исследования показали, что содержание метана в выработанном пространстве достигает $20 \%$ по объему. Вкупе с современными технологиями ведения горных работ, применением высокопроизводительной техники и переходом на системы разработки с уменьшением ширины межлавных целиков наличие газа в выработанном пространстве представляет дополнительную опасность, связанную с возможным возникновением внештатных ситуаций. Данный факт обуславливает актуальность внедрения систем аэрогазовой безопасности калийных рудников.

На панели №8 рудника 4 Рудоуправления ОАО «Беларуськалий» был разработан и реализован проект системы аэрогазовой безопасности и проведен ряд опытных испытаний. Схема размещения оборудования представлена на рис. 2.

В состав системы аэрогазовой безопасности столба лавы вошли:

1. Датчики скорости воздуха для контроля и управления подаваемым на проветривание расходом воздуха.

2. Датчики температуры воздуха для контроля теплового режима лавы: условия ведения горных работ таковы, что температура воздуха в рабочей зоне превышает нормативное значение $+26^{\circ} \mathrm{C}$.

3. Датчики концентрации метана для контроля качественного состава руднтичной атмосферы в рабочей зоне.

4. Две автоматических замерных станции (АЗС), объединяющих каждая несколько датчиков по территориальному и управленческому принципам. АЗС обеспечивают отображение текущей информации с датчиков на дисплее для контроля параметров проветривания персоналом рабочей зоны, прием и передачу информации в информационную сеть рудника и на диспетчерский пункт, связь с базой данных и моделью вентиляционной сети рудника, обеспечение бесперебойной работы, в том числе и передачи информации на поверхность в случае отключения напряжения на подстанции. Первая АЗС располагается непосредственно в рабочей зоне и обеспечивает контроль параметров атмосферы рабочей зоны, вторая АЗС располагается в районе сопряжения с главными выработками и обеспечивает получение фоновых значений контролируемых параметров и работу регулятора воздухораспределения.

5. Автоматическая вентиляционная дверь, выступающая в качестве регулятора воздухораспределения и обеспечивающая управление подачей воздуха на столб лавы.

6. Автоматизированное рабочее место (АРМ) диспетчера для отображения состояния системы и контролируемых параметров, настройки системы и принятия управленческих решений.

7. База данных для хранения измеряемых и расчетных параметров.

8. Вентиляционная модель столба лавы и рудника в аналитическом комплексе «АэроСеть» [4] с учетом размещенного оборудования для расчета требуемых управленческих решений и прогноза развития ситуации.

В рамках проведенных испытаний подтвержден следующий основной функционал системы аэрогазовой безопасности панели №8.

- непрерывный мониторинг параметров рудничной атмосферы в рабочей зоне;

- оповещение диспетчера рудника о выходе контролируемых параметров за пределы допустимых значений и необходимости управления, задействования аварийных режимов проветривания;

- переход в аварийный режим проветривания на основании показаний датчиков системы и прогноза развития ситуации; 
- работа системы аэрогазовой безопасности в рамках системы автоматического управления проветриванием рудника [5];

- динамическое управление проветриванием рабочей зоны на основании показаний датчиков и расчетов, выполненных с использованием модели вентиляционной сети $[6,7]$;

- интеграция с моделью вентиляционной сети столба лавы и рудника [8];

- прогноз развития распространения газовых примесей при возникновении аварийной ситуации с использованием аналитического комплекса «АэроСеть» [9].

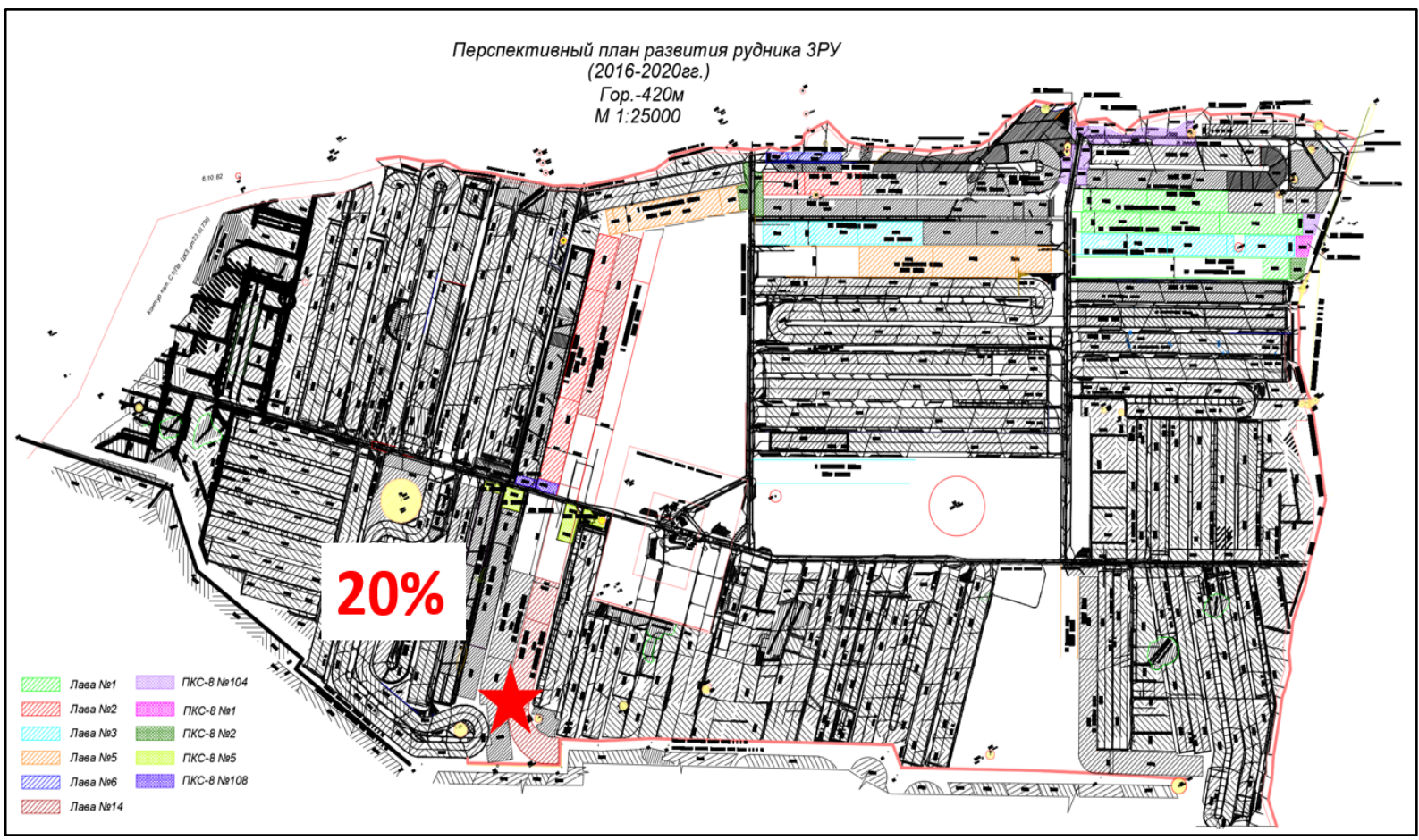

Рис. 1. Исследования газового состава выработанного пространства на плане развития горных работ гор. -420 м рудника 3 РУ ОАО «Беларуськалий»

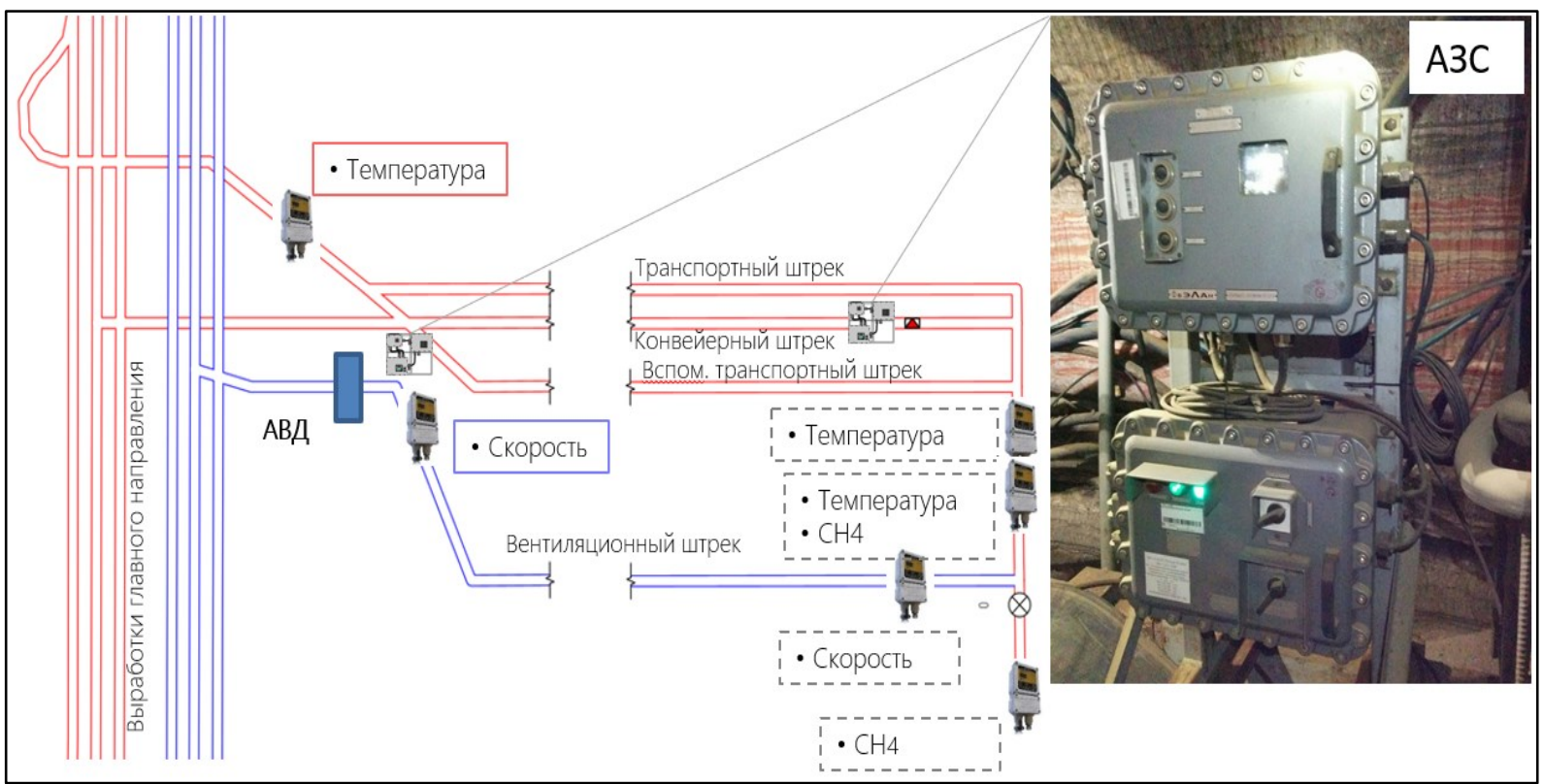

Рис. 2. Схема размещения оборудования на испытаниях системы АГБ 